\title{
Investigation of the effects of thymoquinone on erythrocyte deformability in sepsis treatment which created by cecal perforation in rat
}

\author{
Bostanci $\mathrm{H}^{1}$, Dikmen $\mathrm{K}^{1}$, Comu $\mathrm{FM}^{2}$, Arslan $\mathrm{M}^{3}$, Kucuk $\mathrm{A}^{4}$ \\ Department of General Surgery, Gazi University Medical Faculty, Ankara, Turkey. mustarslan@gmail.com
}

\begin{abstract}
AIM: We aimed to study the effects of thymoquinone on erythrocyte deformability in an experimental model of sepsis given before or after the initiation of the sepsis model.

METHOD: The animals were grouped as $(n=6)$ control, nigella sativa, sepsis, sepsis group with administration of nigella sativa before sepsis development and sepsis group with nigella sativa administration after sepsis development. Cecal ligation and puncture model (CLP) was used to induce sepsis in the animals. The thymoquinone was given 1 hour before or after the CLP in the study groups with a dose of $500 \mathrm{mg} \cdot \mathrm{kg}^{-1}$. Erythrocyte deformability and relative resistance was calculated.

RESULT: Relative resistance was increased in the sepsis groups when compared to the control group ( $p<$ $0.0001)$. Deformability index was increased in the sepsis group when compared to the other groups $(p<0.0001$ in all groups). Sepsis group with after nigella sativa groups deformability index was significantly different from the deformability index in control group $(p=0.002)$. The use of nigella sativa before the initiation of sepsis corrected the deformability index significantly and the results were comparable to the control group ( $p=0.078)$. CONCLUSION: Thymoquinone administration before induction of CLP was observed to have protective effects on these alterations in CLP sepsis (Tab. 1, Fig. 1, Ref. 26). Text in PDF www.elis.sk.

KEY WORDS: sepsis, cecal ligation and perforation, thymoquinone, erythrocyte deformability.
\end{abstract}

\section{Introduction}

Sepsis and sepsis related organ dysfunction are the main reasons for morbidity and mortality encountered in the intensive care unit (ICU) (1). In terms of the clinical picture septic shock among other shock types have the most complicated pathophysiology. In septic shock circulatory insufficiency, inflammation and tendency for coagulation are the mainstay of the disturbed hemostasis (2).

If inflammatory/anti-inflammatory, oxidant/anti-oxidant balance is distorted and if is not corrected in time; reduced vascular tonus, myocardial contractility, cause endothelial dysfunction and result in microcirculatory disturbances and erythrocyte deformability leading to insufficient perfusion (3-5). The oxygenation of the tissues is disturbed and cellular hypoxia leads to shock. Even in ICU admission, impaired RBC rheology (reduced deformability and increased aggregation) has been demonstrated in critically ill patients, especially in those with sepsis $(6-10)$.

${ }^{1}$ Department of General Surgery, Gazi University Medical Faculty, Ankara, Turkey, ${ }^{2}$ Department of Physiology, Kirikkale University Medical Faculty, Kirikkale, Turkey, ${ }^{3}$ Department of Anesthesiology and Reanimation, Gazi University Medical Faculty, Ankara, Turkey, and ${ }^{4}$ Department of Physiology, Dumlupinar University Medical Faculty, Kutahya, Turkey

Address for correspondence: M. Arslan, Dr, Gazi University Faculty of Medicine, Department of Anesthesiology and Reanimation, 06510 Ankara, Turkey.

Phone: +90.312 .2026739$
Thymoquinone is the main constituent of the volatile oil of Nigella sativa (black seed). This compound exists in tautomeric forms including the enol form, the keto form and mixtures. The keto form being the major fraction $(\sim 90 \%)$ as evident by thin layer chromatography (TLC) and high-performance liquid chromatography (HPLC) analyses, and is responsible for the pharmacological properties of thymoquinone. It has been studied for its cardiovascular, respiratory, cytotoxic, anti-inflammatory, and immunomodulatory properties (11).

There have been studies regarding the effect of thymoquinone in sepsis (12-14). However, we did not find any study on its effects on erythrocyte deformability in sepsis. The aim of the present study was to study the effects of thymoquinone on erythrocyte deformability in an experimental model of sepsis.

\section{Material and method}

Animals and experimental protocol

The study was performed upon the approval of Gazi University Experimental Animals Ethics Committee in Gazi University Experimental and Clinical Research Center (GUDAM). All procedures were performed according to the accepted standards of the Guide for the Care and Use of Laboratory Animals.

In this study, 30 male Wistar albino rats weighing between 250 and $300 \mathrm{~g}$, raised under the same environmental conditions, were used. The rats were kept under $20-21^{\circ} \mathrm{C}$ at cycles of 12-hour 
Tab. 1. The design of the study and the organization of the experimental groups.

\begin{tabular}{lll}
\hline Group C & Sham & $\mathrm{n}=6$ \\
\hline Group NS & Sham+ nigella sativa & $\mathrm{n}=6$ \\
\hline Group S & Cecal ligation and perforation & $\mathrm{n}=6$ \\
\hline Group S-BNS & $\begin{array}{l}\text { Cecal ligation and perforation + nigella sativa } \\
(1 \text { hour before the sepsis model) }\end{array}$ & $\mathrm{n}=6$ \\
\hline Group S-ANS & $\begin{array}{l}\text { Cecal ligation and perforation + nigella sativa } \\
(1 \text { hour after the sepsis model) }\end{array}$ & $\mathrm{n}=6$ \\
\hline
\end{tabular}

daylight and 12-hour darkness and had free access to food until 2 hours before the anesthesia procedure.

The animals were randomly separated into five groups, each containing 6 rats: control (group C), nigella sativa group (group NS), sepsis group (group S), sepsis group with before nigella sativa (group S-BNS), and sepsis group with after nigella sativa (group S-ANS) groups.

In the beginning of the experimental procedure anesthesia of the animals was performed by intramuscular injection of 50 $\mathrm{mg} \cdot \mathrm{kg}^{-1} \mathrm{ketamine}$ hydrochloride (Ketalar ${ }^{\circledR}$ flakon, Parke-Davis, USA) and $10 \mathrm{mg} \cdot \mathrm{kg}^{-1}$ xylazine hydrochloride (Alfazyne, $2 \%$, Ege Vet). The surgical procedures were with the animal in supine position and under the heating lamp. After proper aseptic precautions, a midline laparotomy was performed. In the sham group the cecum was isolated, but no perforation was established. In the sepsis groups cecal ligation and puncture (CLP) methods were chosen. Briefly cecum was isolated and ascending colon was manipulated so that the cecum was engorged with fecal material. Following this step, the cecum was ligated by $3 / 0$ silk just below the ileocecal valve. The anterior wall of the cecum was perforated twice by 18 -gauge needle. After the procedure was finished the midline was closed continuously by $3 / 0$ silk. Just prior to closure peritoneal cavity was filled with saline to provide adequate hydration of the animals. In the study groups Thymoquinone was injected intraperitoneally with a $500 \mathrm{mg} \cdot \mathrm{kg}^{-1}$ dose. The experimental groups are summarized in Table 1.

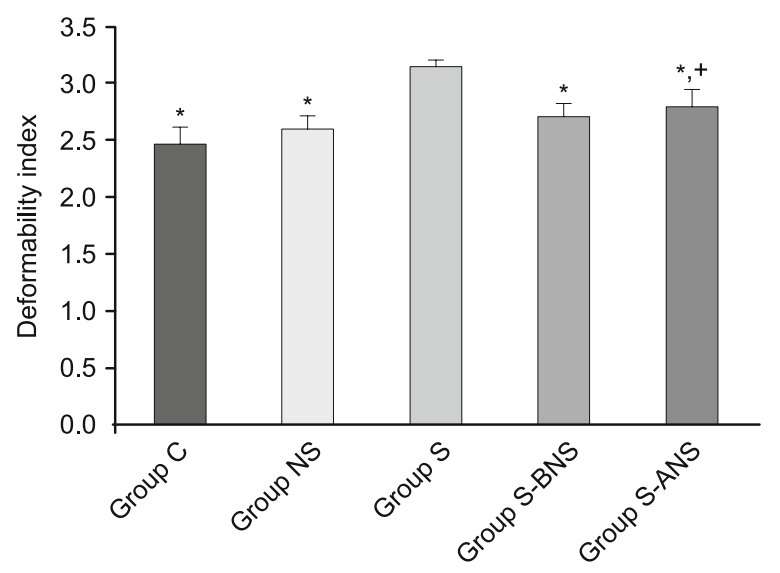

Fig. 1. Erythrocyte deformability values of the groups. Each bar represents mean \pm SD. * $\mathbf{p}<0.05$ compared to Group $\mathrm{S} ;+\mathbf{p}<0.05$ compared to Group C
Twenty four hours after anesthesia procedure, all rats were given ketamine $100 \mathrm{mg} \cdot \mathrm{kg}^{-1}$ intraperitoneally, all rats were killed under anesthesia and heparinized total blood samples were used to prepare erythrocyte packs. Deformability measurements were performed using erythrocyte suspensions with $5 \%$ hematocrit in a phosphate buffered saline (PBS) buffer.

\section{Deformability measurements}

Blood samples were carefully taken, and the measurement process was as fast as possible to avoid hemolysis of erythrocytes. The collected blood was centrifuged at $1000 \mathrm{rpm}$ for ten minutes. Serum and buffy coat on erythrocytes were removed. An isotonic PBS buffer was added to the collapsing erythrocytes and this was centrifuged at $1000 \mathrm{rpm}$ for ten minutes. Liquid on the upper surface was removed. Finally, pure red cell packs were obtained from the washing process, which was repeated three times. Erythrocyte packs were mixed with the PBS buffer to generate a suspension with a value of $5 \% \mathrm{Htc}$. These erythrocyte suspensions were used for the measurement of deformability. Collection and deformability measurements of erythrocytes were performed at $22^{\circ} \mathrm{C}$.

The constant-current filtrometer system was used in the measurement of erythrocyte deformability. Samples to be measured were prepared with $10 \mathrm{ml}$ of erythrocyte suspension and PBS buffer. The flow rate was held constant at $1.5 \mathrm{ml} / \mathrm{min}$ with an infusion pump. A $28 \mathrm{~mm}$ nucleoporin polycarbonate filter with a $5 \mu \mathrm{m}$ pore diameter was preferred. Pressure changes while the erythrocytes passed through the filter were detected by the pressure transducer, and the data was transferred to the computer with the help of an MP30 data equation system (Biopac Systems Inc, Commat, USA). The necessary calculations were performed with related computer programs by measuring the pressure changes at various times. Pressure calibration of the system was performed before each sample measurement. The buffer $\left(\mathrm{P}_{\mathrm{T}}\right)$ and the erythrocytes $\left(\mathrm{P}_{\mathrm{E}}\right)$ were passed through the filtration system and the changes in pressure were measured. The relative refractory period value (Rrel) was calculated by relating the pressure value of the erythrocyte suspension to the pressure value of buffer. Increasing Rrel in the deformability index was interpreted to adversely affect the erythrocytes' deformability.

\section{Statistical analyses}

Statistical Package for the Social Sciences (SPSS, Chicago, IL, USA) 17.0 Program was used for statistical analysis. Kolmogorov-Smirnov test was used for the comparisons to determine the distribution of all variable groups. Variations in erythrocytes deformability were assessed by using Kruskal-Wallis test. Bonferroni adjusted Mann-Whitney U test was used after significant Kruskal-Wallis to determine which group differs from the other. Results were expressed as mean \pm standard deviation (mean $\pm \mathrm{SD}$ ). Statistical significance was set at a $\mathrm{p}<0.05$.

\section{Results}

There was no procedure related mortality among the experimental groups. The relative resistance was increased in the sepsis 
groups as compared to sham group $(\mathrm{p}<0.0001)$. The erythrocyte deformability in Group S was significantly higher than in Groups C, NS, S-BNS and S-ANS ( $p<0.0001$, in all groups). Furthermore, erythrocyte deformability in Group S-ANS was significantly higher than in Group C ( $p=0.002)$. The use of NS before the establishment of sepsis restored the erythrocyte deformability and was comparable to control group $(\mathrm{p}=0.078)$.

\section{Discussion}

Alterations in RBC deformability during sepsis have been reported in animals and in humans $(6,10,15-17)$.

In sepsis, one of the important mechanisms, particularly in cecal ligation and puncture (CLP, a model of polymicrobial sepsis) induced sepsis multiple tissue damage increases with the resultant state of oxidative stress, due to the generation of free radicals and other reactive oxygen species. Oxidants are known to play a major role in inflammation and multiple tissue injury (18).

Homeostatic balance is impaired, overproduction of oxygen free radicals occurs. Thus, the natural scavenging mechanisms, which are the processes that are implicated in microvascular dysfunction, are unbalanced and followed by organ dysfunction including essential organs, such as the lung, kidney, liver, and heart (18-20).

In a sepsis model using cecal-ligation and puncture in rats, Bateman et al (21) reported that reduced RBC deformability was associated with decreased functional capillary density.

Oxidative stress in sepsis has major consequences. One of these is the alteration in the erythrocyte deformability which changes the rheology of the blood leading to microcirculatory disorders (6).

The seeds of NS (family Ranunculaceae), commonly known as black seed or black cumin, have been used as a natural remedy for a number of diseases and conditions such as asthma, cough, bronchitis, headache, eczema, fever, dizziness, influenza, lung inflammation; have contraceptive and anti-inflammatory effects; and have been consumed as condiment $(13,22-25)$.

Powel et al (26) found that tocopherol restored erythrocyte deformability in a sepsis experimental model of cecal ligation and puncture. In the present study we also found that application of thymoquinone restored the erythrocyte deformability. Thymoquinone was especially more effective when applied before the establishment of the sepsis.

In conclusion, the results of this study clearly demonstrated that erythrocyte deformability is significantly altered in experimental CLP sepsis in the rat. This might lead to further problems in microcirculation. Thus, measurement of erythrocyte deformability might have an important impact on the follow-up for CLP sepsis. Additionally, thymoquinone administered before induction of CLP was observed to have protective effects on these alterations in CLP sepsis. Other aspects of these findings, including clinical significance and practical applications, merit further experimental and clinical investigation.

\section{References}

1. Angus DC, Wax RS. Epidemiology of sepsis: an update. Crit Care Med 2001; 29 (Supp1 7): S109-116.

2. Arslantaş MK, Cinel I, Günerli A. Sepsis and extracorporeal membran oxyjenation (ECMO). J Turk Soc Intens Care 2013; 11: 86-92.

3. Cinel I, Opal SM. Molecular biology of inflammation and sepsis: A primer. Crit Care Med 2009; 37 (1): 291-304.

4. Cinel I, Oral U. Sepsiste patojenik mekanizmalar. J Turk Soc Intens Care 2003; 1 (4): 15-28.

5. Cinel IR, Nanda RP. Dellinger. Cardiac dysfunction in septic shock. Yearbook of Intensive Care and Emergency Medicine: Springer Berlin Heidelberg 2008; 43-54.

6. Baskurt OK, Gelmont D, Meiselman HJ. Red blood cell deformability in sepsis. Am J Respir Crit Care Med 1998; 157: 421-7.

7. Kempe DS, Akel A, Lang PA, Hermle T, Biswas R, Lang F. Suicidal erythrocyte death in sepsis. J Mol Med 2007; 85; 273-281.

8. Moutzouri AG, Skoutelis AT, Gogos CA, Missirlis YF, Athanassiou GM. Red blood cell deformability in patients with sepsis: a marker for prognosis and monitoring of severity. Clin Hemorheol Microcirc 2007; 36: 291-299.

9. Piagnerelli M, Boudjeltia KZ, Brohee D, Piro P, Carlier E, Vanhaeverbeek M. Alterations of red blood cell shape and sialic acid membrane content in septic patients. Crit Care Med 2003; 31: 2156-2162.

10. Reggiori G. Occhipinti G, De Gasperi A, Vincent JL, Piagnerelli M. Early alterations of red blood cell rheology in critically ill patients. Crit Care Med 2009; 37: 3041-3046.

11. Salem ML. Immunomodulatory and therapeutic properties of the Nigella sativa L. seed. Int Immunopharmacol 2005; 5: 1749-1770.

12. Bayir Y, Albayrak A, Can I, Karagoz Y, Cakir A, Keles MS. Nigella sativa as a potential therapy for the treatment of lung injury caused by cecal ligation and puncture-induced sepsis model in rats. Cell Mol Biol (Noisy-le-grand) 2012; Suppl 58: OL1680-7.

13. Alici O, Kavakli HS, Koca C, Altintas ND. Treatment of Nigella sativa in experimental sepsis model in rats. Pak J Pharm Sci 2011; 24 (2): $227-231$.

14. Alkharfy KM, Al-Daghri NM, Al-Attas OS, Alokail MS. The protective effect of thymoquinone against sepsis syndrome morbidity and mortality in mice. Int Immunopharmacol 2011; 11 (2): 250-254.

15. Condon MR, Feketova E, Machiedo GW, Deitch EA, Spolarics Z. Augmented erythrocyte band-3 phosphorylation in septic mice. Biochim Biophys Acta 2007; 1772: 580-586.

16. Spolarics Z, Condon MR, Siddiqi M, Machiedo GW, Deitch EA. Red blood cell dysfunction in septic glucose-6-phosphate dehydrogenase-deficient mice. Am J Physiol Heart Circ Physiol 2004; 286: H2118-2126.

17. Piagnerelli M, Boudjeltia KZ, Rapotec A, Richard T, Brohee D, Vanhaeverbeek M. Neuraminidase alters red blood cells in sepsis. Crit Care Med 2009; 37: 1244-1250.

18. Macdonald J, Galley HF, Webster NR. Oxidative stress and gene expression in sepsis. Br J Anaesth 2003; 90: 221-232.

19. Garcia CC, Guabiraba R, Soriani FM, Teixeira MM. The development of anti-inflammatory drugs for infectious diseases. Discov Med 2010; 10: 479-488. 
20. Paterson RL, Webster NR. Sepsis and the systemic inflammatory response syndrome. J R Coll Surg Edinb 2000; 45: 178-182.

21. Bateman RM, Jagger JE, Sharpe MD, Ellsworth ML, Mehta S, Ellis CG. Erythrocyte deformability is a nitric oxide-mediated factor in decreased capillary density during sepsis. Am J Physiol Heart Circ Physiol 2001; 280: H2848-2856.

22. Bayrak O, Bavbek N, Karatas OF, Bayrak R, Catal F, Akcay A. Nigella sativa protects against ischaemia/reperfusion injury in rat kidneys. Nephrol Dial Transplant 2008; 23: 2206-2212.

23. Houghton PJ, Zarka R, de las Heras B, Hoult JR. Fixed oil of Nigella sativa and derived thymoquinone inhibit eicosanoid generation in leukocytes and membrane lipid peroxidation. Planta Med 1995; 61: $33-6.3$
24. Keshri G, Singh MM, Lakshmi V, Kamboj VP. Post-coital contraceptive efficacy of the seeds of Nigella sativa in rats. Indian J Physiol Pharmacol 1995; 39: 59-62.

25. Yoruk O, Ozabacigil Gur F, Uyanik H, Yasar M, Mutlu V, Taysi S. Antioxidant Effects of Nigella Sativa in the Treatment of Experimentally Induced Rhinosinusitis. Maced J Med Sci 2010; 15: 132-137.

26. Powell RJ, Machiedo GW, Rush BF Jr, Dikdan G. Effect of alphatocopherol on red cell deformability and survival in sepsis. Curr Surg 1989; 46 (5): 380-382.

Received November 1, 2017. Accepted December 19, 2017. 